\title{
Optimal Inventory Model for Time Dependent Decaying Items with Stock Dependent Demand Rate and Shortages
}

\author{
Rekha Rani Chaudhary \\ Government Engineering \\ College \\ Bharatpur, Rajasthan, India
}

\author{
Vikas Sharma \\ Banasthali Vidyapith \\ Rajasthan, India
}

\author{
Urvashi Chaudhary \\ D.N. College, Meerut, \\ U.P., India
}

\begin{abstract}
This paper deals with in developing an inventory model for time dependent decaying items as bread, food stuff, green vegetables and medicine etc. The rate of deterioration is time dependent and considers a linear function of time. Demand rate is stock dependent in linear form. It is a common phenomenon observed in the super market that a large pile of goods attracts more customers. Shortages are allowed and shortages are completely backlogged. The numerical example is given to illustrate the model developed. The model is solved analytically by maximizing the total profit.
\end{abstract}

\section{Keywords}

Inventory, EOQ Model, deteriorating items, stock dependent demand rate

\section{INTRODUCTION}

It is usually observed that a large quantity of goods on self in a superstore will lead the customer to buy more goods and that situation create the greater demand of the goods. This situation motivates the retailer to increase their order quantity and the retailers earn the more profit to increase their revenue .In this situation there must arise the problem of space allocation for each item and investment re requirement resulting from the increased inventory levels. The situation become more complex when the inventory is deteriorates in nature. Deterioration of physical goods is one of the important factors in any inventory and production system. The deteriorating items with stock dependent demand rate and shortages have received much attention of several researches in the recent year because most of the physical goods undergo decay or deterioration over time. Commodities such as fruits, vegetables and food stuffs from depletion by direct spoilage wile kept in store. Ghare and Schrader [1963] developed a model for an exponentially decaying inventory. An order level inventory model for items deteriorating at a constant rate was proposed by Shah and Jaiswal [1976].Inventory models with a time dependent rate of deterioration were considered by Covert and Philip [1973]. Some of the significant recent work in this field have been done by Chung and Ting [1993],Fujiwara [1993], , Hariga and Benkherouf [1994], Wee [1995], Giri andChaudhuri[1997], Jalan and Chaudhuri[1999], Structural properties of an inventory system with deterioration and trended demand. Burwell [1997] developed economic lot size model for price-dependent demand under quantity and freight discounts. Inventory model for ameliorating items for price dependent demand rate was proposed by Mondal et.al [2003] and inventory model with price and time dependent demand was developed by You [2005]. In general holding cost is assumed to be known and constant. But in realistic condition holding cost may not Goh [1994] considered various functions to describe holding cost. M. Mandal and M. maiti [1999] considered inventory of damageable items with variable replenishment rate, stock dependent demand and some units in hand. Inventory models for a single deteriorating item with stock dependent demand rate have been studied extensively in the last decade by Datta and pal, Giri and chaudhuri [1998], Padmanabhan and Vrat [1995] Presented inventory models for deteriorating items with stock dependent selling rate and derived the profit functions for both without backlogging and complete backlogging cases. They assumed the selling rate as a function of current inventory level and rate of deterioration as a constant. They assumed the total average cost, warehouse space, inventory cost, purchase and selling prices to be vague and imprecise.

In this paper we developed an economic order quantity (EOQ) in which deterioration rate is linear function of time and shortages are considered as completely backlogged. Demand rate is stock dependent in linear form as $\mathrm{D}(\mathrm{t})=\alpha+\beta \mathrm{I}(\mathrm{t})$. We solve the model to optimized the total profit which is maximum. Model is illustrated with numerical examples.

\section{ASSUMPTIONS AND NOTATIONS}

The fundamental Notations are used to develop the model.

i. $\quad I(t)$ be the inventory level at time $t(0 \leq t<T)$.

ii. $\mathrm{T}$ is the cycle length.

iii. $\mathrm{q}$ is The ordering quantity is.

iv. $\mathrm{A} 0$ is the ordering cost.

v. $\quad \mathrm{s}$ is the selling price per unit item .

vi. $\mathrm{h}$ is the inventory holding cost per unit item per unit time.

vii. $\mathrm{C} 1$ is the shortage cost per unit item per unit time.

viii. $\mathrm{C} 2$ is the deterioration cost per unit item per unit time.

ix. $\quad \mathrm{D}(\mathrm{t})$ is the Demand rate.

x. $\quad \theta(t)$ is the time dependent deterioration rate

xi. $\mathrm{Q}$ is the optimal inventory level.

The fundamental Assumptions are used to develop the model.

For the present Model, it is assumed that

i. Demand $\mathrm{D}(\mathrm{t})$ is dependent on the inventory level or stock dependent in linear form:

$D(t)=\alpha+\beta I(t)$ 
Where $\alpha>0, \quad 0 \leq \beta \leq 1, \quad \beta$ is the stock dependent demand rate parameter

ii. The deterioration rate $\theta(\mathrm{t})$ is dependent on time in linear for

$$
\theta(\mathrm{t})=\mathrm{bt}
$$

iii. The ordering cost $\mathrm{A} 0$ is constant.

iv. The cycle length is assumed $0<\mathrm{t}<\mathrm{T}$.

\section{FORMULATION AND SOLUTION}

The length of the cycle is T. Due to the demand and deterioration of the items the inventory is depleted during time $t \neg 1$. At the time $t 1$ the inventory level becomes zero and shortages occurring in the period $(\mathrm{t} 1, \mathrm{~T})$ which is completely backlogged.

Let $\mathrm{I}(\mathrm{t})$ be the inventory level at time $\mathrm{t}(0 \leq \mathrm{t}<\mathrm{T})$.

The differential equation Can be expressed when the instantaneous state over $(0, \mathrm{~T})$ are given by

$\frac{d I(t)}{d t}+b t . I(t)=-(\alpha+\beta I(\mathrm{t}))$

$$
0 \leq \mathrm{t} \leq \mathrm{t}_{1}
$$

$\frac{d I(t)}{d t}=-(\alpha+\beta I(t))$

$$
\mathrm{t}_{1} \leq \mathrm{t} \leq \mathrm{T}
$$

$$
\text { With I }\left(t_{1}\right)=0 \text { at } t=t_{1}
$$

From equation (1) we get

$$
\begin{aligned}
& \stackrel{I(t)}{=\left[1-\beta t-\frac{b t^{2}}{2}\right]\left[\alpha\left(t_{1}-t\right)+\frac{\beta}{2}\left(t_{1}^{2}-t^{2}\right)\right.} \\
& \left.+\quad \frac{b}{6}\left(t_{1}{ }^{3}-t^{3}\right)\right] \\
& 0 \leq \mathrm{t} \leq \mathrm{t}_{1}
\end{aligned}
$$

From equation (2) we get

$$
\begin{array}{r}
I(t)=[1-\beta t]\left[\alpha\left(t_{1}-t\right)+\frac{\beta}{2}\left(t_{1}^{2}-t^{2}\right)\right] \\
\mathrm{t} 1 \leq \mathrm{t} \leq \mathrm{T}
\end{array}
$$

The holding cost during the time period 0 to 1

$$
\mathrm{H}=H=\int_{0}^{t_{1}} I(t) d t
$$

The total holding cost during the time period 0 to 11

$$
\begin{gathered}
\mathrm{H}=h \cdot \int_{0}^{t_{1}} I(t) d t \\
H=h \int_{0}^{t 1}\left[1-\beta t-\frac{b t^{2}}{2}\right]\left[\alpha\left(t_{1}-t\right)+\frac{\beta}{2}\left(t_{1}^{2}-t^{2}\right)\right. \\
\left.+\frac{b}{6}\left(t_{1}^{3}-t^{3}\right)\right] d t
\end{gathered}
$$

Now total holding cost will be

$$
\begin{array}{r}
H=h\left[\frac{\alpha}{2} t_{1}^{2}+\frac{\beta}{3} t_{1}^{3}\left(1-\frac{\alpha}{2}\right)+\frac{t_{1}^{4}\left(b-\beta^{2}-\alpha b\right)-}{12} b \beta t_{1}^{5}-\frac{b^{2}}{72} t_{1}^{6}\right]
\end{array}
$$

The total deterioration cost during the time period 0 to $\mathrm{t} 1$ is given by

$$
\begin{aligned}
& D_{T}=C_{2} \int_{0}^{t_{1}} \theta(t) \cdot I(t) d t \\
& D_{T}=C_{2} \int_{0}^{t_{1}} b t \cdot\left[1-\beta t-\frac{b t^{2}}{2}\right]\left[\alpha\left(t_{1}-t\right)\right. \\
&\left.\quad+\frac{\beta}{2}\left(t_{1}^{2}-t^{2}\right)+\frac{b}{6}\left(t_{1}{ }^{3}-t^{3}\right)\right] d t
\end{aligned}
$$

Now total deterioration cost will be

$$
\begin{gathered}
D_{T}=C_{2} b\left[\frac{1}{6} \alpha t_{1}^{3}+\beta t_{1}^{4}\left(\frac{1}{8}-\frac{1}{12} \alpha\right)+t_{1}^{5}\left(\frac{b}{20}-\frac{1}{15} \beta^{2}-\right.\right. \\
\left.\frac{1}{40} \alpha b\right)-\beta t_{1}^{6}\left(\frac{1}{36}+\frac{1}{48} b\right)- \\
\left.\frac{1}{112} b^{2} t_{1}^{7}\right]
\end{gathered}
$$

The total shortage cost during the time period $\mathrm{t} 1$ to $\mathrm{T}$ is given by

$$
\begin{gathered}
S h=C_{1} \int_{t_{1}}^{T} I(t) d t \\
S h=-C_{1} \int_{t_{1}}^{T}[1-\beta t]\left[\alpha\left(t_{1}-t\right)+\frac{\beta}{2}\left(t_{1}^{2}-t^{2}\right)\right] d t \\
S h=C_{1}\left[T^{3}\left(\frac{\beta}{6}-\frac{\alpha \beta}{3}\right)+T^{2}\left(\frac{\alpha}{2}+\frac{\alpha}{2} \beta t_{1}+\frac{\beta^{2}}{4} t_{1}^{2}\right)-\right. \\
T\left(\alpha t_{1}+\frac{\beta}{2} t_{1}^{2}\right)-T^{4} \frac{\beta^{2}}{8}+\frac{\alpha}{2} t_{1}^{2}+ \\
\left.\frac{1}{3} \beta t_{1}^{3}\left(1-\frac{1}{2} \alpha\right)-\frac{1}{8} \beta^{2} t_{1}^{4}\right]
\end{gathered}
$$

From equation (5), (6) \& (7) the total profit per unit time can define

$\mathrm{U}\left(\mathrm{T}, \mathrm{t}_{1}\right)=s .(\alpha+\beta I(t))-\frac{1}{T}\left[A_{0}+H+D_{T}+S_{h}\right]$

$\mathrm{U}\left(\mathrm{T}, \mathrm{t}_{1}\right)=\mathrm{s}\left[\alpha+\beta\left\{1-\beta t-\frac{b t^{2}}{2}\right\}\left\{\alpha\left(t_{1}-t\right)+\right.\right.$ $\left.\left.\frac{\beta}{2}\left(t_{1}^{2}-t^{2}\right)+\frac{b}{6}\left(t_{1}{ }^{3}-t^{3}\right)\right\}\right]-\frac{1}{T}\left[A_{0}+h\left\{\frac{\alpha}{2} t_{1}^{2}+\right.\right.$ $\left.\frac{\beta}{3} t_{1}^{3}\left(1-\frac{\alpha}{2}\right)+\frac{t_{1}^{4}}{8}\left(b-\beta^{2}-\alpha b\right)-\frac{1}{12} b \beta t_{1}^{5}-\frac{b^{2}}{72} t_{1}^{6}\right\}+$ $C_{2} b\left\{\frac{1}{6} \alpha t_{1}^{3}+\beta t_{1}^{4}\left(\frac{1}{8}-\frac{1}{12} \alpha\right)+t_{1}^{5}\left(\frac{b}{20}-\frac{1}{15} \beta^{2}-\right.\right.$ $\left.\left.\frac{1}{40} \alpha b\right)-\beta t_{1}^{6}\left(\frac{1}{36}+\frac{1}{48} b\right)-\frac{1}{112} b^{2} t_{1}^{7}\right\}+C_{1}\left\{T^{3}\left(\frac{\beta}{6}-\right.\right.$ $\left.\frac{\alpha \beta}{3}\right)+T^{2}\left(\frac{\alpha}{2}+\frac{\alpha}{2} \beta t_{1}+\frac{\beta^{2}}{4} t_{1}^{2}\right)-T\left(\alpha t_{1}+\frac{\beta}{2} t_{1}^{2}\right)-$ $\left.\left.T^{4} \frac{\beta^{2}}{8}+\frac{\alpha}{2} t_{1}^{2}+\frac{1}{3} \beta t_{1}^{3}\left(1-\frac{1}{2} \alpha\right)-\frac{1}{8} \beta^{2} t_{1}^{4}\right\}\right]$

Our main objective to maximize the profit functio $\mathrm{U}(\mathrm{T}, \mathrm{t} 1)$, the necessary condition for maximize the profit are $\frac{\partial U\left(T, t_{1}\right)}{\partial T}=0$ and $\frac{\partial U\left(T, t_{1}\right)}{\partial t_{1}}=0$ 


$$
\begin{aligned}
& \frac{\partial U\left(T, t_{1}\right)}{\partial T}=0 \\
& +\frac{1}{T^{2}}\left[A_{0}+h\left\{\frac{\alpha}{2} t_{1}^{2}+\frac{\beta}{3} t_{1}^{3}\left(1-\frac{\alpha}{2}\right)+\frac{t_{1}^{4}}{8}\left(b-\beta^{2}-\alpha b\right)-\right.\right. \\
& \left.\frac{1}{12} b \beta t_{1}^{5}-\frac{b^{2}}{72} t_{1}^{6}\right\}+C_{2} b\left\{\frac{1}{6} \alpha T^{3}+\beta t_{1}^{4}\left(\frac{1}{8}-\frac{1}{12} \alpha\right)+\right. \\
& t_{1}^{5}\left(\frac{b}{20}-\frac{1}{15} \beta^{2}-\frac{1}{40} \alpha b\right)-\beta t_{1}^{6}\left(\frac{1}{36}+\frac{1}{48} b\right)- \\
& \left.\left.\frac{1}{112} b^{2} T^{7}\right\}\right]-\left[C _ { 1 } \left\{\frac{2 T}{3}\left(\frac{\beta}{2}-\frac{\alpha \beta}{1}\right)+\frac{\alpha}{2}+\frac{\alpha}{2} \beta t_{1}+\frac{\beta^{2}}{4} t_{1}^{2}-\right.\right. \\
& \left.\left.3 T^{2} \frac{\beta^{2}}{8}-\frac{1}{T^{2}} \frac{\alpha}{2} t_{1}^{2}-\frac{1}{3 T^{2}} \beta t_{1}^{3}\left(1-\frac{1}{2} \alpha\right)+\frac{1}{8 T^{2}} \beta^{2} t_{1}^{4}\right\}\right]=0
\end{aligned}
$$

$$
\text { And } \frac{\partial U\left(T, t_{1}\right)}{\partial t_{1}}=0
$$

$\mathrm{s} \beta\left[\alpha+\beta t_{1}+\frac{1}{2} b t_{1}^{2}-\alpha \beta t_{1}-\beta^{2} t t_{1}-\frac{1}{2} \beta b t t_{1}^{2}-\right.$

$\left.\frac{\alpha}{2} b t^{2}-\frac{\beta}{2} b t_{1} t^{2}-\frac{b^{2}}{4} t^{2} t_{1}^{2}\right]-\frac{1}{T}\left[h\left\{\alpha t_{1}+\right.\right.$

$\beta t_{1}^{2}\left(1-\frac{\alpha}{2}\right)+\frac{1}{2} t_{1}^{3}\left(b-\beta^{2}-\alpha b\right)-\frac{1}{12} b t_{1}^{4}(5 \beta+$

$\left.\left.b t_{1}\right)\right\}+C_{2} b\left\{\frac{1}{2} \alpha t_{1}^{2}+\beta t_{1}^{3}\left(\frac{1}{2}-\frac{1}{3} \alpha\right)+t_{1}^{4}\left(\frac{b}{4}-\frac{1}{3} \beta^{2}-\right.\right.$

$\left.\left.\frac{1}{8} \alpha b\right)-\frac{\beta t_{1}^{5}}{2}\left(\frac{1}{3}+\frac{1}{4} b\right)-\frac{1}{16} b^{2} t_{1}^{6}\right\}+C_{1}\left\{T\left(\frac{\alpha}{2} \beta+\right.\right.$

$\left.\frac{\beta^{2}}{2} t_{1}\right)-\left(\alpha+\beta t_{1}\right)+\frac{1}{T} \alpha t_{1}+\frac{1}{T} \beta t_{1}^{2}\left(1-\frac{1}{2} \alpha\right)-$

$\left.\left.\frac{1}{2 T} \beta^{2} t_{1}^{3}\right\}\right]$

With the software mathematica-5.1, compute the optimal value of $\mathrm{T}^{*}$ and $\mathrm{t}_{1} *$ simultaneously by equation no. (9) and equation no. (10) .The optimal value of profit function $\mathrm{U}^{*}(\mathrm{~T}$, $t_{1}$ ) is determined by equation no. (8). The optimal value of $\mathrm{T}^{*}$ and $\mathrm{t}_{1} *$ satisfy the sufficient conditions for maximizing profit function $\mathrm{U}^{*}\left(\mathrm{~T}, \mathrm{t}_{1}\right)$ are.

$$
\frac{\partial^{2} U\left(T, t_{1}\right)}{\partial T^{2}}<0, \quad \frac{\partial^{2} U\left(T, t_{1}\right)}{\partial t_{1}^{2}}<0
$$

$$
\text { And } \begin{aligned}
\frac{\partial^{2} U\left(T, t_{1}\right)}{\partial T^{2}} \cdot \frac{\partial^{2} U\left(T, t_{1}\right)}{\partial t_{1}^{2}}-\frac{\partial^{2} U\left(T, t_{1}\right)}{\partial T \partial t}>0 \text { And at } \mathrm{T}=\mathrm{T}^{*} \\
\text { optimal value } \mathrm{t}_{1}=\mathrm{t}_{1}{ }^{*}
\end{aligned}
$$

\section{NUMERICAL EXAMPLE}

Example-1. Let us consider $A=400, \alpha=200, \beta=$ $0.3, b=0.2, h=1.2, \mathrm{C}_{1}=1.1, C_{2}=0.02$

Based on above input data and Using the software mathematica-5.1, calculate the optimal value of $\mathrm{U}^{*}\left(\mathrm{~T}, \mathrm{t}_{1}\right), \mathrm{T}^{*}$ and $t_{1} *$ simultaneously by equation no. (8), equation no. (9) And equation no. (10).

$$
\mathrm{U}^{*}\left(\mathrm{~T}, \mathrm{t}_{1}\right)=1379.62, \mathrm{~T}^{*}=2.8031, \mathrm{t}_{1}^{*}=1.6482
$$

Example -2 Let us consider $A=350 \alpha=150, \beta=$ $0.21, b=0.17, h=1.1, \mathrm{C}_{1}=1.4, C_{2}=0.01$

$$
\mathrm{P}\left(\mathrm{T}, \mathrm{t}_{1}\right)=1281.50, \quad \mathrm{~T}^{*}=2.22141, \mathrm{t}_{1} *=1.48592
$$

\section{SENSITIVITY ANALYSIS}

We have study the effects of changes of the parameters on the optimal values of $\mathrm{S}(\mathrm{T}, \mathrm{t} 1), \mathrm{T}^{*} \& \mathrm{t} 1 *$ derived by proposed method .The sensitivity analysis is performed in view of the numerical example given above. We have executed sensitivity analysis by changing the parameters $a, b, \alpha$, and $\beta$ as $+20 \%$ $,+50 \%,-20 \%$ and $-50 \%$. All remaining parameters have original values with respect to these changes. The corresponding changes in $\mathrm{S}(\mathrm{T}, \mathrm{t} 1) \mathrm{T}^{*} \& \mathrm{t} 1 *$ are showed in below table. 1

\begin{tabular}{|c|c|c|c|c|}
\hline parameters & $\begin{array}{c}\% \\
\text { change }\end{array}$ & $\mathrm{T}^{*}$ & $\mathrm{t}_{1}{ }^{*}$ & $\mathrm{~S}\left(\mathrm{~T}, \mathrm{t}_{1}\right)$ \\
\hline \multirow{6}{*}{$\mathrm{a}$} & -50 & 3.95571 & 2.58215 & 78.1315 \\
& -20 & 2.97069 & 2.08240 & 771.315 \\
& +20 & 3.00993 & 1.70750 & 2508.6869 \\
& +50 & 3.08009 & 1.91768 & 4110.4955 \\
\hline \multirow{6}{*}{$\alpha$} & -50 & 2.95645 & 2.02388 & 1589.5347 \\
& -20 & 2.87390 & 2.12810 & 1570.8666 \\
& +20 & 3.67173 & 1.93818 & 1565.3933 \\
& +50 & 3.76248 & 1.94990 & 1545.7257 \\
\hline \multirow{6}{*}{$\beta$} & -50 & 3.39729 & 2.22046 & 1499.6804 \\
& -20 & 3.30004 & 1.86548 & 1500.3134 \\
& +20 & 3.20408 & 1.91124 & 1550.1047 \\
& +50 & 3.10878 & 1.75736 & 1553.5795 \\
\hline \multirow{6}{*}{$b$} & -50 & 5.01628 & 1.99738 & 342.3532 \\
& -20 & 4.87102 & 1.87911 & 967.1480 \\
& +20 & 3.00856 & 1.75506 & 3998.8802 \\
& +50 & 3.19306 & 1.63501 & 2599.5976 \\
\hline
\end{tabular}

We study above table.1 brings out the following.

We observed that as parameter $\mathrm{a}$ and $\mathrm{b}$ increase, optimal value of $\mathrm{T}^{*}$ and $\mathrm{t} 1^{*}$ decrease while the average total profit $\mathrm{S}(\mathrm{T}, \mathrm{t} 1)$ of an inventory system increases, whereas parameter $a$ and $b$ decrease, optimal value of $\mathrm{T}^{*}$ and $\mathrm{t} 1 *$ increase while the average total profit $\mathrm{S}(\mathrm{T}, \mathrm{t} 1)$ of an inventory system decreases. It is interesting to observe that deterioration parameter $\alpha$ increase, optimal value of $\mathrm{T}^{*}$ and $\mathrm{t} 1 *$ increase while the average total profit $\mathrm{S}(\mathrm{T}, \mathrm{t} 1)$ of an inventory system decreases. If deterioration parameter $\alpha$ decrease, optimal value of $\mathrm{T}^{*}$ and $\mathrm{t} 1 *$ decrease while the average total profit $\mathrm{S}(\mathrm{T}, \mathrm{t} 1)$ of an inventory system increases. Second deterioration parameter $\beta$ increase, optimal value of $\mathrm{T}^{*}$ and $\mathrm{t} 1^{*}$ decrease while the average total profit $S(T, t 1)$ of an inventory system increases. If deterioration parameter $\beta$ decrease, optimal value of $T^{*}$ and $\mathrm{t} 1 *$ increase while the average total profit $\mathrm{S}(\mathrm{T}, \mathrm{t} 1)$ of an inventory system decreases. 


\section{GRAPHICAL REPRESENTATION OF CONCAVITY OF THE PROFIT FUNCTION}

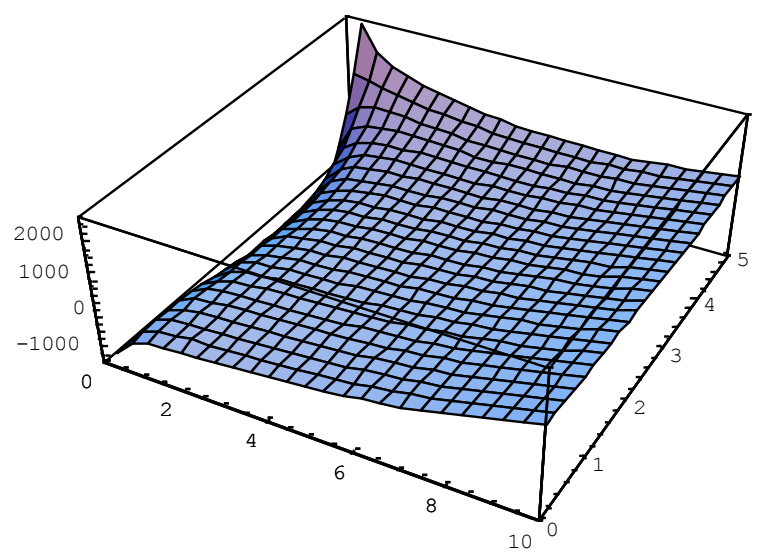

Fig. 1

\section{REFERENCES}

[1] Ghare, P.M., and Schrader, G.F., "An inventory model for exponentially deteriorating items", Journal of Industrial Engineering, 14(1963), 238-243.

[2] Shah, Y.K., and Jaiswal, M.C., "An order-level inventory model for a system with Constant rate of deterioration", Opsearch, 14(1977), 174-184

[3] Covert, R.P., and Philip, G.C., "An EOQ model for items with Weibull distribution deterioration. AIIE Transactions", 5(1973), 323-326.

[4] Chung, K., and Ting, P., "A heuristic for replenishment of deteriorating items with a linear trend in demand", Journal of the Operational Research Society,44(1993), $1235-1241$

[5] Fujiwara, O., "EOQ models for continuously deteriorating products using linear and exponential penalty costs", European Journal of Operational Research, 70(1993), 104-14.

[6] Hariga, M.A., and Benkherouf, L., "Optimal and heuristic inventory replenishment models for deteriorating items with exponential time- varying demand", European Journal of Operational Research. 79(1994), 123-137.
[7] Wee, H.M., "A deterministic lot-size inventory model for deteriorating with shortages and a declining market", Computers and Operations, 22(1995), 345-356.

[8] Jalan, A.K., and Chaudhuri, K.S., "Structural properties of an inventory system with deterioration and trended demand", International Journal of Science, 30(1999), 627-633.

[9] Giri, B.C., and Chaudhuri, K.S., "Heuristic models for deteriorating items with shortages and time varying demand and costs", International Journal of Systems Science, 28(1997), 53-159.

[10] Burwell T.H., Dave D.S., Fitzpatrick K.E., Roy M.R., "Economic lot size model for price-dependent demand under quantity and freight discounts", International of Production Economics, 48(2)(1997), 141-155.

[11] Mondal, B., Bhunia, A.K., Maiti, M., "An inventory system of ameliorating items for price dependent demand rate", Computers and Industrial Engineering, 45(3)(2003), 443-456.

[12] You, S.P., "Inventory policy for products with price and time-dependent demands", Journal of the Operational Research Society, 56(2005), 870-873. Journal of the Operational Research Society, 56(2005), 870-873.

[13] Goh, M., EOQ models with general demand and holding cost functions", European Journal of Operational Research, 73(1994), 50-54.

[14] Mondal, B., Bhunia, A.K., Maiti, M., "An inventory system of ameliorating items for price dependent demand rate", Computers and Industrial Engineering, 45(3) (2003), 443-456.

[15] T.K. Datta, A.K. Pal, deterministic inventory systems for deteriorating items with inventory level dependent demand rate and shortages, opsearch 27(1990) 213-224.

[16] Giri, B.C., and Chaudhuri, K.S., Deterministic models of perishable inventory with stock dependent demand rate and nonlinear holding cost, European Journal of Operational Research. 105(1998), 467-474.

[17] G. Padmanabhan , P. Vrat, EOQ models for perishable items under stock dependent selling rate, European Journal of Operational Research. 86(1995), 281-292. 